\title{
Teaching International Students in English. A Matter of Culture
}

\author{
Jane MatTisson \\ School of Teacher Education, \\ Kristianstad University College, \\ Sweden
}

Received: 2 June 2009 / Accepted: 6 October 2009

ISSN: $1697-7467$

\begin{abstract}
There is a growing interest in learning in the multicultural classroom. More and more universities offer a wide variety of programmes and courses in English. It is important to understand the influence of cultural factors on student performance in the multicultural classroom. This article discusses the writer's experience of teaching an intercultural communication course at Kristianstad University College, Sweden. It also presents an in-service course, "Teaching in English", for lecturers and teachers whose mother tongue is not English. The second half of the article focuses on Chinese postgraduates and discusses the cultural factors affecting their performance in writing classes.
\end{abstract}

Key words: multicultural, socio-educational, academic writing, cultural influence

\section{Enseñanza en inglés a alumnos internacionales. Un tema cultural}

RESUMEN: En la actualidad hay un creciente interés en el aprendizaje en clases multiculturales. Cada vez más universidades ofrecen una amplia variedad de programas y cursos en inglés. Desde esta perspectiva, es importante entender la influencia de los factores culturales sobre el rendimiento del estudiante en aulas multiculturales. Este artículo trata sobre la experiencia de la escritora al enseñar un curso de comunicación intercultural en la Universidad de Kristianstad, Suecia. También describe un curso de formación sobre escritura académica en inglés tanto para profesores de universidad como todo profesor cuya lengua materna no es el inglés. La segunda mitad del artículo se centra en cursos de postgrado chinos y analiza los factores culturales que afectan al rendimiento en las clases de escritura.

Palabras clave: Multicultural, socio-educativo, escritura académica, influencia cultural.

\section{INTRODUCTION}

Over the past twenty years university classrooms in the West have become increasingly multicultural. Sweden is no exception. The writer is a senior lecturer of English at Kristianstad University College, south-east Sweden. She specialises in academic writing and conducts workshops 
on how to write academic essays and theses, most recently at the University of Murcia, Spain. A number of questions are posed in the present article: How can we facilitate learning in the academic writing classroom? What can universities do to help teachers understand the problems which students from cultures as diverse as Spain, South America, Germany and China encounter in mastering the techniques of writing summaries, reports, essays and theses in English? In attempting to provide some answers to these questions I discuss my experience of teaching the intercultural communication course (7.5 ECTS credits) at Kristianstad University College, as well as teaching Chinese students in Sweden and in China. Before discussing these courses I briefly present, by way of a context, a 7.5-credit course, "Teaching in English", developed by myself and specially designed for university lecturers who teach international students. It is a sobering but at the same time encouraging conclusion that "expert professional communicators are those who have come to appreciate their lack of expertise" (Peter Trudgill, introduction to Ron and Suzanne Wong Scollon's Intercultural Communication, 2001, n.p.). The problems of international students are also the teacher's problems. These are, I believe, particularly great in the field of academic writing. And it is in the latter field that they have particularly serious consequences as the written text is one of the primary means by which students demonstrate their knowledge.

\section{Culture and the socio-educational model}

Fundamental to the following discussion is the nature of culture and how it influences students' performance in the multicultural classroom. Culture is used here in its anthropological sense to refer to customs and traditions, ideology, forms of discourse and social organisation. As Lixian Jin and Martin Cortazzi argue, "culture is a pattern of normal ways of doing things, what people expect and how people interpret situations in which their expectations are not met" (1996:206). Approximately one quarter of the world's population speak and/or write English. English is "recognized by more countries as a desirable lingua franca than any other language" (Crystal, 2001:6). Variations in the kinds of English spoken and written around the world are enormous. As a result, recognition of diversity and the establishment of acceptable standards have become imperative. It is necessary for pedagogy to be flexible. A model is required which incorporates the social and educational factors involved in teaching and learning a second language.

The present article is based on R.C. Gardner's socio-educational model. This has been selected because it takes into consideration the cultural/symbolic elements of a different ethnolinguistic community. While the model specifically addresses the situation of the L2 (second language) learner, it can equally well be applied to all learning in an international, English-speaking environment. Briefly, the model can be described as follows. There are four interrelated aspects of L2 learning: the social and cultural environment; individual differences among learners; the setting; and learner outcomes (in Ellis, 1994). Students' beliefs about language and culture are determined by their social and cultural environment. According to Gardner, individual learner differences are determined primarily by motivation and language aptitude ${ }^{1}$. Where motivation is encouraged, and language proficiency is integrated with cultural

1. The socio-educational model identifies a set of variable and a means of assessing these "so that specific hypotheses about the nature and influence of motivation in second language learning can be evaluated". R.C. 
values, beliefs and attitudes, L2 proficiency can be increased. As Ellis demonstrates, the strength of Gardner's model is that it explains the relationship between setting and proficiency by identifying a number of intervening variables, including attitudes, motivation and self-confidence. It is with attitudes and motivation that the present article is chiefly concerned.

Briefly, Gardner argues that attitudes relate to the learning situation and concern "any aspect of the situation in which the language is learned" (2001:8). These aspects include "the teacher, the course in general, one's classmates, the course materials, extra-curricular activities, activities associated with the course, etc." (2001:8).The focus of Gardner's model is on differences in attitude towards the learning situation. Motivation, Gardner argues, is "the driving force in any situation. In English as a Second Language teaching Gardner identifies three levels of motivation: the drive to expend effort to learn the language; the desire to achieve success; and enjoyment of learning, which is the result of motivation. The most successful learner is one who exhibits what Gardner describes as "integrative motivation", i.e. "one who is motivated to learn the second language, has a desire or willingness to identify with the other language community, and tends to evaluate the learning situation positively" (2001:9).

Cultural beliefs, according to Gardner, influence attitudes towards the learning situation. These affect motivation which, combined with the individual learner's language aptitude, can result indirectly in both linguistic and non-linguistic outcomes. Such outcomes develop in both formal and informal learning contexts. It is with the former that this article is concerned. The fundamental assumption is that some contexts are more likely to result in successful L2 learning than others. A successful L2 learning context is based on the principle that "[u]nderstanding other ways of seeing things is understanding each other and understanding each other is a highly efficient way of assisting each other in understanding things better" (J. Bowden and F. Marton, 1998:293). International students bring to the classroom a variety of social and academic cultures, different levels of motivation and aptitude, different expectations, a variety of views of what is appropriate behaviour in the classroom, and different opinions about what constitutes "good" spoken and written English. It is these aspects of L2 teaching and learning which are explored in the above-mentioned "Teaching in English" course at Kristianstad University College.

\section{Teaching in english, 7.5 CRedits}

The "Teaching in English" course is designed specifically for practising university teachers ${ }^{2}$ whose mother tongue is not English. It focuses on oral and written English and provides practical exercises in teaching and supervising international students in the multicultural classroom. The course participants are drawn from a variety of programmes and disciplines. Common to all is that they teach in English since many of their students do not speak Swedish. On completion of the course, the participants are expected to have achieved:

A clearer understanding of how diversity in the multicultural classroom affects the nature of learning and knowledge as well as relationships between teachers and students.

Gardner, "Language Learning Motivation: The Student, the Teacher and the Researcher". (2001). Texas Papers in Foreign Language Education, 6, 1-18 (1).

2. The course is also offered as a separate course to secondary- and high-school teachers. 
A greater understanding of how a common teaching language, English, affects students' comprehension of information and their ability to express ideas/ formulate arguments. Appreciation of their own weaknesses and strengths in a) expressing themselves in English in the classroom and b) modifying their language to suit specific teaching methods, e.g. lectures, tutorials and seminars.

The participants share their experience of teaching courses in English, discuss problems encountered and reflect on lessons learned. I am sorry, I do not understand what you would like me to do!

Course participants write and present instructions for specific classroom tasks and projects in English. They also write two essays, on "The challenges of teaching in the multicultural classroom", and "Facilitating learning in the multicultural classroom where the language of instruction is English". In addition, they write and deliver an oral presentation on a subject of relevance to their particular discipline. Feedback on both the written and oral tasks is provided by the teacher and by the course participants. A variety of teaching situations are simulated, e.g. lectures, seminars, and group discussions. Course participants consider how they respond to the different situations and teaching styles and also reflect on the consequences for learning. The perspectives of both student and teacher are discussed.

The course book comprises Jude Carroll's and Janette Ryan's Teaching International Students. Improving Learning for All (2005). It explores the challenges presented to both students and teachers by the multicultural classroom. The book combines practical advice with pedagogic theory and includes such topics as the experience of the international student, the nature of learning and teacher-student relationships, development of teaching skills, multicultural group work, and postgraduate supervision. The course participants are encouraged to reflect on how culture (social as well as academic) affects motivation and learner outcomes and on how English as the language of instruction influences teaching and learning in the formal context of the classroom.

Carroll and Ryan argue that we have much to learn from international students, that the latter function as "canaries in the coalmine" (an expression dating from the time when miners carried canaries with them when working underground. The canaries were extremely sensitive to poor air quality). International students point to aspects of our teaching that all students, domestic as well as international, may regard as a challenge. In so doing, we have an opportunity to change conditions in the classroom, to the benefit of all students in higher education.

International Students. Improving Learning for All also draws attention to the importance of confidence. The culture shock which so many students experience when beginning a programme or course in a foreign environment causes dips in confidence: initially students tend to underestimate the difficulty of adapting to a new environment, of being taught in a kind of English which may differ from that to which they are used in the homeland, and of acclimatising themselves to an academic context which adopts unfamiliar rules and which places different and unanticipated expectations on them. Initially they may overrate their level of English and general knowledge, only later to go to the other extreme, leading to a confidence crisis which may seriously inhibit adaptation and learning.

An additional problem is that traditional language tests such as TOEFL and IELTS do not test students' knowledge of academic language. Participants on the course "Teaching in English" discuss the nature and conventions of this language and how to facilitate students' understanding 
and mastery of its rules. Academic writing is a particularly challenging area for the international student. Carroll and Ryan argue that teachers must consider carefully "the role of writing in their classrooms and the resources student writers bring to the tasks they are set" $(2005: 63)$. They point to a widely-held belief that there is a clear definition of "good writing". This is a highly complex problem. Bourdieu et al., for example, argue that "academic language . .. is no one's mother tongue" (1994:8) as it is a specialised form of academic discourse belonging to a community which in itself incorporates a number of sub-communities. Each such community has its own special form of discourse or language. The second half of the present article discusses the conventions of a specific academic sub-community, that of English literary specialists. First, however, I shall briefly describe the above-mentioned intercultural communication course which I teach at Kristianstad University College. The courses discussed here demonstrate the importance of Gardner's model and its emphasis on the relationship between the environment and students' beliefs about language and culture.

\section{InTERCUltural COMmunication, 7.5 CREDits}

The intercultural communication course at Kristianstad University College is based on the four principles of intercultural communication outlined by Ron and Suzanne Wong Scollon:

Humans are not all the same.

At least some of these differences among them show culturally or socially predictable patterns.

At least some of these patterns are reflected in patterns of discourse.

Some of these differences in discourse patterns lead directly to unwanted social problems such as intergroup hostility, stereotyping, preferential treatment, and discrimination (2001:169).

The intercultural communication course attracts students from a variety of countries, including Spain, the U.S.A., Canada, China, Vietnam, Korea, Pakistan, India, Germany, France, the Netherlands, Lithuania, Estonia, Latvia, Poland and the Czech Republic. The course is offered twice a year, once in the spring and once in the autumn term, and the number of participants has risen steadily for the last five years. Guest lecturers with different ethnic backgrounds are invited to give lectures on the culture, social as well as academic, of their respective countries. They come from Great Britain, China, Germany, and the Baltic countries. The students discuss among themselves and with the teacher key points raised during lectures and are given written assignments based on the latter. The course concludes with a short thesis (30 pages) on a subject of the student's choice; this must, however, be related to the importance of communication in a cultural context. Project topics range from teacher/student interaction in Spain, business communication in China, student/teacher communication in higher education in Germany, and cultural influences on educational practices in Poland. Students are allocated a supervisor, who has expert knowledge within the student's chosen field and who is responsible for ensuring that students follow the formal project instructions issued at the beginning of term. Students and supervisors meet regularly both in group seminars and on an individual basis. The final project is submitted at the end of term. Whereas most students reach a level of proficiency 
in writing that enables them to achieve at least a "Pass" grade, some (approximately 15\%) fail. Students who fail tend to be those who neither attend the supervisory seminars nor the class sessions. They have not taken advantage of the opportunity to explore differences between their own culture and that of the new teaching situation in which they find themselves in Sweden. Neither have they learned the conventions of writing an academic thesis as they have not studied and discussed the detailed instructions handed out at the beginning of the course. Such cases serve to demonstrate the importance of sharing knowledge and experience in class discussions and seminars.

Students' previous experience of writing essays and short theses has considerable influence on their progress in writing the final thesis. European and North American students share certain basic academic standards in writing; their thinking is inductive (the nature and importance of this kind of thinking are discussed shortly in relation to Chinese students); they expect to write a thesis with a linear argument; they have learned the importance of acknowledging sources, and they are used to working in seminars and under a personal supervisor. European and North American students are comfortable with asking questions and are not afraid to admit when they do not understand. As the following discussion of Chinese students will show, such is not the case with Asian students, who need special support ${ }^{3}$.

\section{Chinese students and english literary essays. Levels III AND IV, KRISTIANSTAD UNIVERSITY COLLEGE}

Chinese students of English from our partner university in Ningbo, south-east China, are selected by the home university on the basis of language proficiency (they are tested using the IELTS test and must have a minimum score of 5) as well as on the academic and linguistic quality of their bachelor thesis (written in English). The students discussed here are all English majors. Most have never travelled abroad before, and for all, studying at a Western university is a new experience. Students admitted to the level-III course (30 ECTS credits. Autumn term) stay for one year, to complete the level-IV course (30 ECTS credits. Spring term). For successful candidates, the level-IV course results in the award of a Master of English degree.

3. It is for this reason that I have developed an introductory course specifically for Chinese students (undergraduates as well as postgraduates) at Kristianstad University College.Very briefly, "An Introduction to Academic Studies in English" (12 ECTS credits) runs throughout the summer and focuses on differences between academic practices in China and the West. Cultural issues affecting performance in the classroom are an important element of the course. Students learn about the different ways of thinking in Asia and the West, academic practices, and also different relationships between students and teachers. Language proficiency, written as well as oral, is an important element of the course. Students learn how to prepare and deliver an oral presentation, take notes at lectures, structure linear arguments, take a separatist rather than an holistic view of a text, adopt a straightforward and non-embellished style, and acknowledge primary and secondary sources correctly. Those who study the "Introduction to Academic Studies in English" course fall into two categories: they come directly from high school, or they have studied for four years at university and possess a bachelor's degree. They do not intend to study English: the majority wish to enter computer, technology and economic programmes. Some have taken formal English tests, e.g. TOEFL or IELTS, but many have not. The students on the "Introduction to Academic Studies in English" are to be distinguished from the Chinese students of English discussed in the section "Chinese Students and English Literary Essays". 
The following discussion focuses on Chinese students' essay writing practices at postgraduate level.

In order to write a level-III essay students must have a knowledge of theory. Two compulsory courses are given in Kristianstad, one on linguistic theory and the other on literary theory. On completion of both courses, students decide if they wish to write their essay on a linguistic or a literary topic. The essay comrpises half of the credits (15) of the level-III course. The ensuing discussion focuses on literary essays.

I present the students with a level-III literary essay compendium compiled by myself. In the introduction I address the nature of a literary essay. Following is an excerpt from the introduction:

You are required to select a topic worthy of 15-20 A4 pages of writing and many hours and days of your time. You will organise your thoughts into a logical and persuasive argument which is expressed in standard formats and according to accepted practices.

As you develop your thoughts and argument and study your primary and secondary sources, you will find that new ideas occur to you. This will be a source of exhileration as well as frustration, and there will come a point when you must say "stop", i.e. you must limit yourself to the ideas and sources you feel should be included in your essay given the time constraints.

You will also experience the condition known as "writer's block". Most writers come to a point in their writing when they feel they cannot continue. This is normal! It is also something you must learn to conquer. It is tempting to say, "I shall wait for inspiration". Do not wait: write! You can always remove material at a later stage. Inspiration is not a gift from above: it is the result of effort and persistence.

At level III you are not required to conduct an original argument. Your task is to demonstrate that you can organise your thoughts and research into a coherent argument which is supported by quotations from your primary and secondary texts. You will demonstrate an ability to tackle a complex issue, break it down into logical units which can be discussed coherently and thoroughly, subject the units to sustained and focused discussion, and present the results of this process in a coherent text with a convincing conclusion. When you have acquired these skills, you will find that they are useful not only at the university but also for all kinds of writing in many different situations (2000:1).

The compendium also addresses the issue of language.

The ability to write correct English is important at this level. Your degree is in English! Good English is the result of a careful choice of words, correct grammar, spelling and punctuation, and the employment of an appropriate style. It cannot be over-emphasised how important it is to work with a peer and to revise your essay over and over again. Choose a peer who will tell you the truth! Use a grammar and spell checker. Consult a dictionary whenever you are in doubt about the correct use of a word and its accompanying pronoun, preposition etc. (2).

While the above comments are written for all students following the level-III course, they have particular relevance for Chinese students. To return to Gardner's model, Chinese students 
have very particular beliefs about language and culture as the result of a specific social and academic culture. I offer extra sessions to the Chinese students, during which we focus on cultural differences and how these influence writing performance. We discuss, for example, the importance of adopting a holistic $v s$ separtist view of a text, the difference between deductive $v_{s}$ inductive thinking, why it is necessary to restrict metaphorical language, and when and how one should acknowledge sources. I shall briefly address each of these aspects in turn and consider their relevance to teaching academic writing.

\subsection{High-context vs. low-context cultures}

China is a so-called high context culture in which inference and implicitness are the source of meaning; it is the reader's and not the writer's responsibility to interpret meaning. In a high-context culture, meaning may be unspoken. Chinese writing may be seen by Westerners to be ambiguous, the message is behind rather than in the language itself. This contrasts clearly with the low-context culture of the West, where meaning is explicit, cause is discussed before effect, and argument is linear (See R. Kaplan, 1996: 1-20).

Chinese students adopt a holistic view when analysing and tend to perceive on the basis of an overall pattern uniting objects or ideas. Opposites may be part of a larger truth. Chinese students tend to think in terms of both/and rather than the either/or alternative favoured by Western-style binary thinking. In the West, a more analytical, separatist view is adopted in which objects or ideas are decomposed into parts and common attributes identified (See Bond, 1991:18-25). For Chinese students, the main aim of communication is to create harmonious relationships rather than share information. Inductive patterns of communication are used in which the background comes first, the main point later, and reasons before results. Proof can come from analogy, examples or indications. In the West, there is a general consensus that the main point is stated first, results come before reasons, and proof is provided by explicit sequential links. In China, communication defers to tradition and authority; originality and spontaneity, are of less significance.

\subsection{Deductive vs. inductive thinking}

The preferred method of thinking in China is deductive and not inductive as in the West. This is an important difference which has profound implications for how to teach essay writing to Chinese students. Deduction involves beginning with first principles which are taken for granted. It uses a logic which reasons downwards in order to derive propositions; because these contain no inferences or new information, they must by definition be true. Induction, on the other hand, has as its starting point empirically verifiable facts and/or statistics. It uses these to reason upwards in order to produce conclusions or theories which are regarded as tentative since more facts may become available (See Wenzhong and Grove, 1991: 73-86).

\subsection{Source management}

Chinese students are taught that reproduction of an author's words and ideas brings honour to the author. The greater the author, the more important it is to cite his ideas and words. The use of inverted commas in China is much freer than in the West: an author's words may be reproduced almost verbatim without using inverted commas. 


\subsection{Implications for essay writing}

What then are the implications of the above differences in thinking and praxis for essay writing? When the Chinese student places background first and the main point later in the belief that the latter cannot be understood without the "necessary" background, a Western tutor is likely to be confused or frustrated. If students are instead encouraged to appreciate the importance of the introductory paragraph as an identifier of the main point of the essay, as is the praxis in Western rhetoric, subsequent misunderstandings will be avoided. Students can be taught to use basic introductory statements like "This essay discusses ..." or "This essay focuses on ..." In a discussion of a famous novel, for example, the introductory statement might read: "This essay discusses the relationship between love and marriage in Jane Austen's Pride and Prejudice". Students may work in pairs or small process-writing ${ }^{4}$ groups to discuss the implications of the introductory statement and develop/identify a specific thesis. The latter may be expressed as "This essay argues that Darcy learns that love is more important than social position or financial security when choosing a partner. By marrying Elizabeth Bennett Darcy clearly defies social convention." Once the introductory and thesis statements have been formulated, students should be encouraged to identify the scope of their essay by stating the main topics to be covered. The basic structure of the essay is thus established in the first paragraph and the reader is clearly informed of the order of points to be discussed. The progression is linear, and attention is paid to the links between paragraphs to ensure smooth transitions from point to point.

The above system assumes inductive thinking in which it is the responsibility of the writer to establish unambiguous meaning expressed in clear, non-metaphorical language. The essay outlined above posits a view of Pride and Prejudice which is based on close analysis of textual evidence. It requires students to think creatively and build a linear argument with a minimum input of background information and maximum emphasis on textual analysis. Process writing enables one to steer students' efforts from the very beginning and ensure that they have a clear structure and argument with which to work. It is the writer's experience that this strategy presents no problems for Chinese students. It is, however, important for Western tutors to recognise that the approach may be unfamiliar to them. Tutors must be able to anticipate problems. Chinese tutors in the home country can also prepare their students for the Western system and discuss differences and their implications.

Chinese students must also be taught western principles of source management. This is not simply a matter of learning a particular style sheet such as MLA (Modern Language Association) or MHRA (Modern Humanities Research Association) but also when to acknowledge sources. Lecturers must understand that students do not necessarily wish to deceive: they have a different view of what constitutes plagiarism ${ }^{5}$. Before we accuse a student of plagiarism, we should be familiar with the practices prevailing in the student's home country.

4. This method has proved highly successful at Kristianstad University College. Students write limited sections of their essay, these are peer-reviewed and also submitted to the teacher for comments. Initially the focus is on the introduction, specifically the thesis statement, as well as the overall structure of the essay. Students write a few pages at a time. This way, they gain in confidence and potential problems are discovered at an early stage.

5. See Lars-Erik Nilsson. (2008). "But can't you see they are lying”: Student moral positions and ethical practices in the wake of technological change. Göteborg: Acta Universitatis Gothoburgensis. 


\subsection{Obstacles}

One important obstacle for Chinese students in the multicultural classroom is the emphasis on rote learning which has traditionally characterised the Chinese educational system. According to the Chinese view, memorisation is a concession to the collected experience of the past and to the authority of others. For Western tutors the method is old-fashioned and detrimental to cultivating understanding and analysis. While memorisation does not preclude understanding indeed it is seen by Chinese tutors as a means of gaining knowledge which can be further developed at a later stage and used for creation - it takes the focus off penetrating below the surface to discover deeper meanings, broader themes, underlying assumptions and different argumentative directions ${ }^{6}$; in other words, it inhibits the acquisition of the very skills which are fostered within the Western system of essay and thesis writing.

Above all, memorisation hinders creativity and critical thinking as these are understood in the West. Students of all nationalities must be taught to close read. This is particularly problematical for Chinese students who need extra help with concept formation and information processing. Close reading also requires a high level of language sophistication in order to discuss particular words and expressions or stylistic devices. Chinese students are clearly at a disadvantage when the culture in which they live has relatively little exposure to the English language. It is thus particularly important for Chinese students to work in small groups where they have maximum opportunity to discuss texts with fellow students, test their hypotheses and benefit from the advantages of more individual guidance from the tutor.

An additional problem worthy of mention is the overuse of metaphors. Studies (see Myers, 2000, for example) indicate that Chinese students believe that the more metaphors there are in a text, the more effective is the writing. In Western tradition, metaphors are used sparingly and effectively. From the Chinese perspective, metaphors allow the reader to draw more than one meaning from a statement, thereby rendering the latter more convincing. In the Western tradition, ambiguity is thought to confuse or blur meaning and is normally punished with a low grade.

\section{Chinese essay Writing. LeVel iv}

The essay at this level comprises a Master's thesis of between 35 and 40 pages. Unlike level III, the subject is neither linguistic nor literary. The focus at level IV is on learning and teaching English as a Second Language. The course comprises both literary and linguistic elements. Students are given supervision in group seminars rather than on an individual basis, as is the practice at level III. They are encouraged to share experiences and learn from one other. As mentioned earlier, half of the credits for the course comprise the thesis. In the first two modules students study the theory and practice of English as a Second Language (Module A), and Test Procedures (Module B. This module focuses on testing grammar and vocabulary).

6. For a wider discussion of the implications of memorisation as a learning tool in Chinese society see Jimmy Chan, "Chinese Intelligence," chapter 7 in Michael Harris Bond (Ed.) (1996). The Handbook of Chinese Psychology. Hong Kong: Oxford University Press, pp. 93-108. 
Many of the skills learned while writing a literary or a linguistic essay at level III are incorporated into the level-IV course; however, the latter also requires students to conduct independent research into a selected aspect of learning or teaching English as a Second Language.

The independent nature of the research at level IV, along with the change in teaching method (group seminars rather than individual supervision), pose special problems for the Chinese students. They are used from an early age to the teacher telling them what to do. At level IV, students must select their own topic and group to be investigated, decide on the method(s) of investigation, identify and select relevant secondary sources, and analyse data independently. The essay conventions applying to level III also apply to level IV.

Students who have had problems in completing their level-III essay find particular difficulty in completing the level-IV essay due to the independent nature of the investigations and the lack of individual tuition (students can contact their supervisor outside seminar sessions, but only where there is a serious problem). There is insufficient time between the two levels for the students to improve their language skills radically. Those who fail to achieve a "pass" grade for their level-IV essay must rely on the support of a language corrector. Language correction work is completed in China; students re-submit their essays in Sweden. It is possible to revise the essay several times ${ }^{7}$.

Experience of teaching Chinese students at levels III and IV substantiates Gardner's principle that the expectations of international students are determined by the environment. While the Chinese students gradually learn to appreciate the differences between Western and Chinese academic writing practices, this takes time. And one year is not always sufficient for students to make the necessary adjustments. It may take them a further 6 months after completion of the course to re-write and edit their essays so that they comply with the standards set at Kristianstad University College. This process can be frustrating for student and examiner alike.

Teaching Chinese students makes it extremely clear that it is very important for teachers to understand the culture from which their students come. This can, of course, be partially accomplished by background reading. The best experience, however, is that gained at firsthand. By teaching in China on a regular basis it is possible to build up knowledge of how Chinese academic culture works and thereby anticipate and, to some extent prevent problems.

\section{ESSAY WRITING AT NINGBO UNIVERSITY}

Each year I teach a four-week course in English literature and English literary theory at Master's level at Ningbo University. The course is an integral part of Ningbo University's Master of English Literature programme. At the end of the course, students write a short thesis (15 pages) on a selected literary topic. The course literature comprises an electronic book written by myself ("Literary Theory and the English Canon. An Introduction for Master of English Students at Ningbo University". See HYPERLINK «http://home.hkr.se/ maj/ningbo/» http://home.hkr.se/ maj/ningbo/ 2005. Currently under revision $)^{8}$.

7. It is normally necessary to revise the essay twice before it is passed.

8. The overwhelming number of literary texts on the internet are written by male authors. I am currently investigating the availability of texts by female authors. The individual chapters on the different genres are also being extended. 
Students come to Ningbo from all over China. Some have a background in literary theory, others do not. The shortage of books in English in China has prompted me to select texts which are freely available on the internet. My electronic book contains an introductory chapter, a chapter on literary theory and academic writing, literary theory in practice (practice texts), structuring, writing and peer reviewing, and a series of short chapters covering the following genres: poetry, the essay, drama, the short story and the novella. A list of literary definitions is also provided. The URLs for all the texts studied in class are to be found in the electronic book. Before discussing each text I give a short lecture on its social and historical context and its significance as a canonical text (all texts are important works from the English literary canon). Students discuss the texts in seminar groups, using questions provided by myself (these are distributed separately). They select one of the texts as the subject of their thesis. Before I leave China, students meet me in seminars to discuss their topic, how their thesis is to be structured, which aspects of the primary text they will focus on, and the theoretical perspective from which they will discuss their chosen text. Students submit a draft of their essay before I leave China. They continue to work on their essays for a further two months, at the end of which period they submit them to me by e-mail.

Since the students come from different universities with different academic practices (there are major differences between universities in urban and rural areas in China), there are a number of cultural barriers to be surmounted at the beginning of the course. And, as already mentioned, for some of the students, literary theory is a totally new topic. As Gardner demonstrates, motivation is an important aspect of learning. The motivation of the Ningbo students is extremely high. Students devote many hours a day to their English studies. They also meet me individually after normal university hours to discuss their work. Success is important not only for academic satisfaction; it is a prerequisite for finding lucrative employment after graduation. The environment, both social and academic, stimulates the students to work to their best ability. And such students tend to remain in contact with their teacher long after their studies are complete. I receive mails from Ningbo students several years after visiting them in Ningbo. Often their communication concerns academic subjects (they need advice about sources, how to work with a particular topic or theory etc.) as well as more personal issues. Through continued mail contact the students learn more about literature and writing, and I improve my knowledge of Chinese academic culture. Learning is mutual and ongoing.

\section{Final remarks}

This article discusses the relationship between culture and academic Is it the second sentence which has been removed? I cannot see how you can jump from the first to the third sentence? experience/performance. It focuses on essay writing, specifically within the field of English literature. Much of what has been said about literature, however, concerns all subjects taught at our universities. Peter Trudgill's observation quoted at the beginning remains true: "expert professional communicators are those who have come to appreciate their lack of expertise." Surely this is a healthy sign? Helping international students to achieve well in the Western system is a complex but not insoluble problem. As teachers we need to discuss the theory and practice of teaching in the multicultural classroom. We also need to visit other countries, learn about their cultures, visit universities in different countries and discuss with 
colleagues at home and abroad how best to facilitate learning for international students. This is why courses such as the earlier-described "Teaching in English" are so important. And this is why books such as Carroll's and Ryan's Teaching International Students have a very important place in our universities. The penultimate chapter (15) suggests ways of increasing the pool of knowledge and expertise within teams of teachers and departments. I conclude with a few examples of Carroll's and Ryan's advice: It is necessary to invite experts to give lectures and lead seminars. In-service courses provide a forum for discussion and can act as catalysts for innovation and improvement. Workshops on teaching international students are an effective means of sharing experience. Finally, reading journals such as the one in which this article is published plays an important rôle in disseminating knowledge and experience. English is the lingua franca in the world today. Much energy is devoted to helping students learn to speak the language. Less attention is devoted to promoting good writing practices. This is indeed a shame as writing is our heritage and our gift to the next generation. It is an integral part of our learning and an important way of demonstrating and preserving our knowledge. Without good writing practices, there is little hope of succeeding in the academic world.

\section{REFERENCES}

Bond, Michael Harris. (1991). Beyond the Chinese Face. Insights From Psychology. Hong Kong: Oxford University Press.

Bourdieu, P. et al. "Introduction: Language and the relationship to language in the teaching situation". In Pierre Bourdieu et al. Academic Discourse: Linguistic Misunderstanding and Professorial Power.

Bourdieu, P. et al. (1994). Academic Discourse: Linguistic Misunderstanding and Professorial Power. Cambridge: Polity Press.

Bowden, J. and F. Marton. (1998). The university of learning. Beyond quality and competence. London: Kogan Page.

Brown, A. Ed. (2000). English in Southeast Asia 99. National Institute of Education, Singapore.

Burns, A. and Coffin, C. Eds. (2001). Analysing English in a Global Context. A Reader. London: Routledge.

Carroll, J. and Ryan, J. Eds. (2005). Teaching International Students. Improving Learning for All. London: Routledge.

Crystal, D. "The Future of Englishes." In Burns, A. and C. Coffin. Analysing English in a Global Context. A Reader.

Ellis, R. (1994). The Study of Second Language Acquisition. Oxford: Oxford University Press.

Gardner, R.C. "Language Learning Motivation: The Student, the Teacher and the Researcher". (2001). Texas Papers in Foreign Language Education, 6, 1-18.

Hewings, M. and Dudley-Evans, T. Eds. (1996). Evaluation and Course Design in EAP. Hemel Hempstead: Phoenix ELT.

Jin, Lixian. and M. Cortazzi. "This Way is Very Different From Chinese Ways: EAP Needs and Academic Culture". In Martin Hewings and Tony Dudley-Evans (Eds.), Evaluation and Course Design in EAP.

Kaplan, R. (1996). "Cultural thought patterns in intercultural education", Language Learning 16, $1-2: 1-20$. 
Mattisson. J. (2005). "Literary Theory and the English Canon. An Introduction for Master of English Students at Ningbo University”. HYPERLINK «http://home.hkr.se/ maj/ningbo/» http://home.hkr.se/ maj/ningbo/ . Visited 1 June 2009

Mattisson, J. (2000). "Writing and Defending a level-III essay". Unpublished compendium. Kristianstad University College.

Myers, James L., "Rhetorical style: Chinese encounter Aristotle". In A. Brown (Ed.), English in Southeast Asia 99.

Nilsson, Lars-Erik. (2008). "But can't you see they are lying": Student moral positions and ethical practices in the wake of technological change. Göteborg: Acta Universitatis Gothoburgensis.

Scollon, R. and Scollon, S.W. (2001). Intercultural Communication. Malden, U.S.A.: Blackwell Publishing.

Wenzhong, H. and C. L. Grove. (1991). Encountering the Chinese. A Guide for Americans. Yarmouth, U.S.A.: Intercultural Press. 